\title{
Effect of Zr Addition on the Corrosion Behavior of Extruded Mg Alloys in NaCl Solution
}

\author{
Seok-Hoan Jeong ${ }^{1}$, Byung-Jin Kim ${ }^{1}$, Hyun-Kyu Lim² ${ }^{2}$, Won-Tae Kim ${ }^{3}$, Do Hyang Kim ${ }^{1}$ \\ and Soon-Hyeok Jeon ${ }^{4, *}$ \\ ${ }^{1}$ Department of Materials Science and Engineering, Yonsei University, \\ 134 Shinchon-dong, Seodaemun-gu, Seoul 120-749, Republic of Korea \\ ${ }^{2}$ Rare Metal R\&BD Group, Korea Institute of Industrial Technology, Incheon, Republic of Korea \\ ${ }^{3}$ Department of Optical Engineering, Cheongju University, 36 Naedok-Dong, Cheongju 360-764, Republic of Korea \\ ${ }^{4}$ Nuclear Materials Research Division, Korea Atomic Energy Research Institute, \\ 989-111 Daedeok-daero, Yuseong-gu, Daejeon 305-353, Republic of Korea
}

The effect of $\mathrm{Zr}$ addition on the corrosion behavior of an extruded Mg-10Gd-1Zn alloy (GZ101) in 3.5 mass\% NaCl solution was investigated by electrochemical and immersion tests in 3.5\% NaCl solution. The addition of 1 mass\% $\mathrm{Zr}$ to GZ101 (to afford GZ101-1Zr) decreased the fraction of $14 \mathrm{H}$ (number of stacking layers and H-Hexahedral structure) and lamellar long period stacking ordered (LPSO) phases across the $\alpha$-Mg matrix and increased the fraction of the X-phase $\left(\mathrm{Mg}_{12} \mathrm{GdZn}\right)$ formed at grain boundaries. Extruded GZ101-1Zr exhibited a significantly smaller corrosion rate than extruded GZ101 ( $0.13 \mathrm{vs.} 2.11 \mathrm{~mm}^{-} \mathrm{year}^{-1}$ ) due to containing less $14 \mathrm{H} /$ lamellar LPSO phases (detrimental to corrosion resistance) and featuring a noble $\{10 \overline{1} 0\}$ prismatic texture in the extrusion direction. [doi:10.2320/matertrans.M2017329]

(Received October 31, 2017; Accepted December 15, 2017; Published February 2, 2018)

Keywords: magnesium alloy, zirconium, extrusion, corrosion, weight loss

\section{Introduction}

The use of lightweight structural materials provides a solution to a number of environmental problems, improves the energy efficiency of certain processes (e.g., of those employed in the fabrication of automobile parts) and therefore has attracted increased attention. For example, the superior mechanical properties of magnesium alloys have made them a popular research subject, ${ }^{1)}$ despite their applications still being limited by poor high-temperature performance and corrosion resistance. ${ }^{2-4)}$

The corrosion resistance and mechanical properties of magnesium alloys have been widely investigated. ${ }^{4-6)}$ Srinivasan et al. showed that the addition of rare earth (RE) elements improves the strength and corrosion resistance of the above alloys. ${ }^{4)}$ Moreover, such property improvement is also greatly affected by the presence of long periodic stacking order (LPSO) structures observed in $\mathrm{Zn}$-containing Mg-RE alloys. 5,6)

In addition, the corrosion resistance of wrought $\mathrm{Mg}$ alloys is also significantly influenced by their texture, since it affects the atomic packing density and crystallographic anisotropy in the hexagonal close-packed (HCP) structure of these alloys. $^{7,8)}$ The surface normal direction of the plate has a predominant basal texture developed through the rolling process, which shows a more stable surface than the cross-section surface in the $\mathrm{NaCl}$ aqueous solution environment of the previously reported. ${ }^{7)}$

In particular, the effect of secondary (e.g., I-, W-, and X-) phases on the microstructure and mechanical properties of ternary $\mathrm{Mg}-\mathrm{Gd}-\mathrm{Zn}$ alloys has been extensively investigated. ${ }^{9,10)}$ However, studies dealing with the corrosion resistance of such alloys are still scarce. $\mathrm{Zr}$ doping is a very ef-

*Corresponding author, E-mail: junsoon@kaeri.re.kr fective method of improving tensile elongation via grain refinement. In the case of Al-free alloys, $\alpha$-Mg nuclei form on the surface of $\mathrm{Zr}$ nuclei due to the role of nuclei in casting and grain refinement is caused. ${ }^{9,11)}$ However, the optimization of $\mathrm{Zr}$ content in Mg-RE alloys is still underexplored. ${ }^{12,13)}$

Herein, we describe how the corrosion resistance of $\mathrm{Mg}$ alloys can be improved by $\mathrm{Zr}$ addition and extrusion, by subjecting extruded samples placed in 3.5 mass\% aqueous $\mathrm{NaCl}$ to electrochemical corrosion and immersion tests and further probing their properties by field emission scanning electron microscopy (FE-SEM) coupled with energy-dispersive X-ray scatter (EDS) and electron backscatter diffraction (EBSD) analyses.

\section{Experimental Procedure}

Ingots with a nominal composition of Mg-10Gd-1Zn-xZr (here and subsequently, the above numbers/notation correspond to mass \%; $\mathrm{x}=0$ and 1.0) were prepared by adding $\mathrm{Mg}-39 \mathrm{Gd}$ and $\mathrm{Mg}-33.3 \mathrm{Zr}$ master alloys to molten $\mathrm{Mg}$ (99.9 mass\%) contained in a BN-coated steel crucible held in an electrical furnace under a dynamic protective gas $\left(\mathrm{SF}_{6}+\mathrm{CO}_{2}\right)$ atmosphere to prevent $\mathrm{Mg}$ oxidation. The melt was held at $1023 \mathrm{~K}$ for $40 \mathrm{~min}$ and stirred for $1 \mathrm{~min}$ before casting into a $\mathrm{BN}$-coated steel mold preheated to $473 \mathrm{~K}$ to produce billets (diameter $=42 \mathrm{~mm}$, length $=135 \mathrm{~mm}$ ). The above billets were homogenized at $783 \mathrm{~K}$ for $12 \mathrm{~h}$ and cooled by warm water at $353 \mathrm{~K}$ to afford "ST" samples, being subsequently subjected to hot extrusion at $703 \mathrm{~K}$, a ram speed of $2.5 \mathrm{~mm} / \mathrm{s}$, and an extrusion ratio of 10:1 to afford "AE" samples. Samples with dimensions of $50 \times 5 \times 2 \mathrm{~mm}^{3}$ were used for the immersion test, with those utilized for the electrochemical corrosion test being about 50-mm-long with a diameter of $11 \mathrm{~mm}$. Finally, the as-prepared samples were 
polished with $\mathrm{SiC}$ paper and rinsed with ethanol.

The microstructural analysis was performed by FE-SEM (JEOL, JSM-7001F) coupled with EDS and EBSD (EDAXTSL, Digiview). The fractions of secondary phases were measured by analyzing (Image J 1.48) SEM images for at least five areas of each sample. Quantitative secondary phase EDS analysis was performed at different randomly selected locations, and the results were expressed as average with standard deviation.

The immersion test was performed in 3.5 mass \% aqueous $\mathrm{NaCl}$ at $298 \mathrm{~K}$, and the produced corrosion products were removed using a solution of $\mathrm{CrO}_{3}(200 \mathrm{~g}), \mathrm{AgNO}_{3}(10 \mathrm{~g})$, and $\mathrm{Ba}\left(\mathrm{NO}_{3}\right)_{2}(20 \mathrm{~g})$ in deionized water $(1000 \mathrm{~mL})$. The corrosion rates were expressed in millimeters per year $(\mathrm{mm}$ year $^{-1}$ ) was evaluated by measuring the weight change after immersion test. ${ }^{14)}$ Electrochemical corrosion tests were carried out in 3.5 mass\% aqueous $\mathrm{NaCl}$ at $298 \mathrm{~K}$ according to ASTM G 5. ${ }^{15)}$ The test cell comprised a working electrode, a glass capillary probe connected to a saturated calomel reference electrode (SCE), and two graphite rod counter electrodes, and testing was conducted within a potential range of -2.0 to $-1.0 \mathrm{~V}$ vs. SCE at a scan rate of $1 \mathrm{mV} / \mathrm{s}$.

\section{Results and Discussions}

Figure 1 shows low- and high-magnification SEM images of ST samples. As shown in Figs. 1(a) and (c), the Mg$10 \mathrm{Gd}-1 \mathrm{Zn}$ (further referred to as GZ101) alloy comprised four phases, namely $\alpha$-Mg, Mg5Gd, 14H LPSO (Yamasaki found that $14 \mathrm{H}$-type LPSO phase formed in $\mathrm{Mg}_{97} \mathrm{Zn}_{1} \mathrm{Gd}_{2}$ (at\%) alloy, who showed a stacking sequence of ABABABACBCBCBC with a period) ${ }^{16,17)}$, and lamellar LPSO. However, the Mg-10Gd-1Zn-1Zr alloy (further referred to as GZ101-1Zr; Figs. 1(b) and (d)) was markedly different from GZ101. In particular, the addition of $\mathrm{Zr}$ decreased the contents of $14 \mathrm{H}$ LPSO $(1.33 \rightarrow 0.51 \mathrm{vol} \%)$, lamellar LPSO $(3.8 \rightarrow 1.83$ vol\%), and Mg5Gd $(0.83 \rightarrow$ $0.45 \mathrm{vol} \%)$ phases, increasing that of the $\mathrm{X}$ phase $(2.6 \rightarrow$ 3.86 vol\%). Moreover, GZ101-1Zr exhibited an increased total secondary phase fraction $(6 \rightarrow 6.7 \mathrm{vol} \%)$ and contained
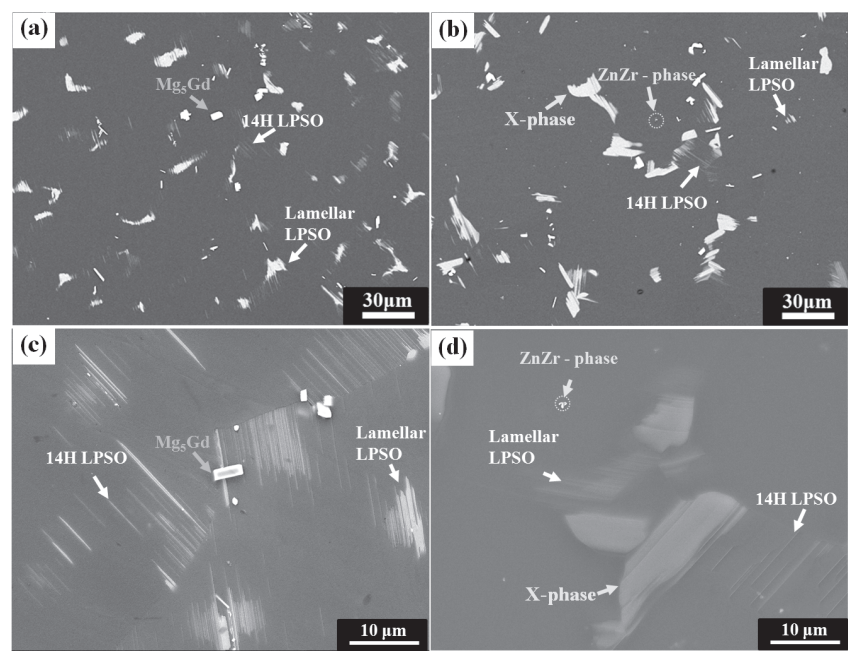

Fig. 1 SEM micrographs of the solution heat treated alloys : (a and c) GZ101 and (b and d) GZ101-1Zr. a $\mathrm{ZnZr}$ phase formed at the center of $\alpha-\mathrm{Mg}$ grains. The chemical compositions of all phases were in good agreement with those determined previously (Table 1). ${ }^{9,13,18)}$

Figure 2 shows SEM images of AE samples, revealing that extrusion-induced microstructure deformation and recrystallization were observed for both alloys. Moreover, the fractions of $14 \mathrm{H}(0.13 \mathrm{vol} \%)$ and lamellar (1.55 vol\%) LPSO phases decreased in as-extruded GZ101, with as-extruded GZ101-1Zr containing $0.51 \mathrm{vol} \%$ of the lamellar LPSO phase. Interestingly, the above phases were split into small particles aligned in the extrusion direction, whereas $\mathrm{X}$-phase (3.8 vol\%) particles were almost unaffected by extrusion, being only slightly elongated in the extrusion direction. Additionally, banded bulk $\beta$ phase formation was also observed, as reported previously, ${ }^{19)}$ with the total secondary phase fractions in as-extruded GZ101 and GZ101-1Zr equaling 9.8 and $11.5 \mathrm{vol} \%$, respectively.

Figure 3 presents EBSD images and pole figures of extruded GZ101 and GZ101-1Zr, showing that dynamic recrystallization during extrusion resulted in the formation of recrystallized microstructures, which were more homogenously distributed and fine-grained in the case of extruded GZ101-1Zr (Figs. 3(c) and (d)). In addition, Figs. 3(e) and (f) show that the average grain size of extruded GZ101 $(\sim 24.58 \mu \mathrm{m})$ was smaller than that of extruded GZ101-1Zr $(\sim 70.32 \mu \mathrm{m})$. The $(0001)$ basal and $(10 \overline{1} 0)$ prismatic pole figures indicate that the addition of 1 mass $\% \mathrm{Zr}$ to GZ101 decreased the maximum basal pole intensity due to inducing

Table 1 Average chemical compositions of the intermetallic compounds formed on the experimental alloys by using SEM-EDS.

\begin{tabular}{ccccc}
\hline \multirow{2}{*}{ Intermetallic compounds } & \multicolumn{5}{c}{ Chemical composition (at\%) } \\
\cline { 2 - 5 } & $\mathrm{Gd}$ & $\mathrm{Zn}$ & $\mathrm{Zr}$ & $\mathrm{Mg}$ \\
\hline $\mathrm{Mg}_{5} \mathrm{Gd}$ & 17.8 & - & - & Balance \\
14H LPSO & 2.6 & 1.5 & - & Balance \\
Lamellar LPSO & 5.6 & 3.9 & - & Balance \\
X-phase & 10.8 & 7.0 & - & Balance \\
ZnZr & 1.9 & 0.4 & 0.4 & Balance \\
\hline
\end{tabular}

Table 2 Electrochemical corrosion parameters obtained from potentiodynamic polarization curves of the extruded alloys.

\begin{tabular}{ccccc}
\hline Alloys & $\mathrm{i}_{\text {corr }}\left(\mu \mathrm{A} / \mathrm{cm}^{2}\right)$ & $\mathrm{E}_{\text {corr }}(\mathrm{V})$ & $\beta_{\mathrm{c}}(\mathrm{mV} /$ dacade $)$ & $\beta_{\mathrm{a}}(\mathrm{mV} /$ dacade $)$ \\
\hline GZ101 & 81.8 & -1.57 & 254 & 88 \\
GZ101-1Zr & 4.2 & -1.82 & 98 & 104 \\
\hline
\end{tabular}
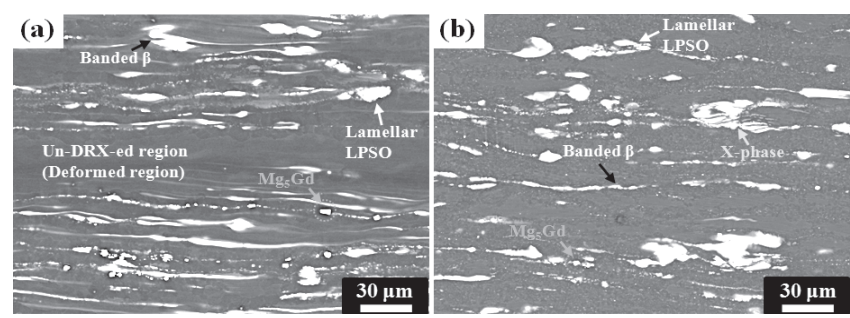

Fig. 2 SEM micrographs of the as extruded alloys: (a) GZ101 and (b) GZ101-1Zr. 


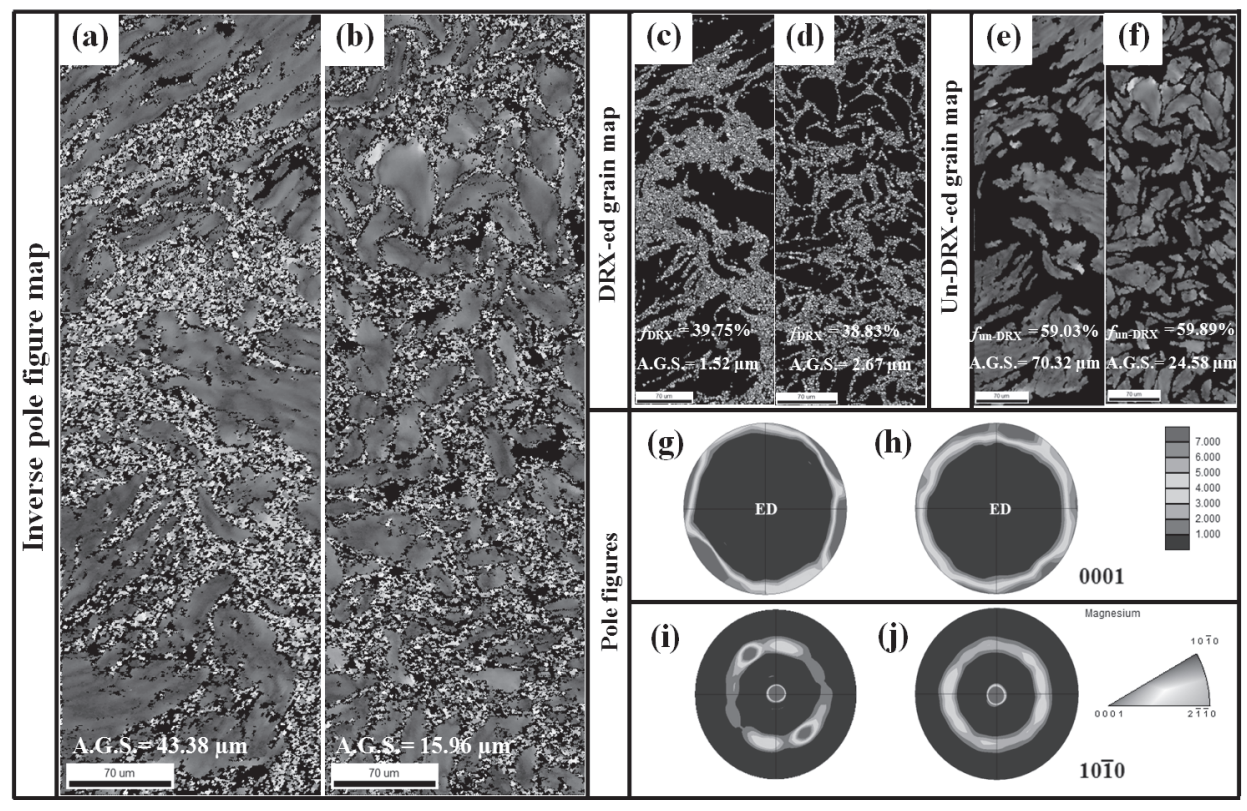

Fig. 3 EBSD data of the cross section of the as extruded samples of alloys: (a and b) inverse pole figure maps, (c and d) DRX-ed grain map, (e) (f) unDRX-ed grain map and pole figures of the cross section $(\mathrm{g})-(\mathrm{j})$ of each of the GZ101 and GZ101-1Zr alloys, respectively.

dynamic recrystallization, but deformed grain distribution became homogeneous with small size to the direction of extrusion (Figs. 3(g)-(j)). Based on the above results, the addition of $\mathrm{Zr}$ favored the development of a $\{10 \overline{1} 0\}$ prismatic texture in the extrusion direction and resulted in the basal plane being inclined to the sample normal direction of the extruded alloy.

Figure 4 shows the corrosion morphologies obtained after the seven-day immersion test of extruded alloys and their potentiodynamic polarization curves in 3.5 mass $\%$ aqueous $\mathrm{NaCl}$ at $298 \mathrm{~K}$. As shown in Fig. 4(a), extruded GZ101-1Zr featured a more stable corrosion morphology than extruded GZ101, additionally exhibiting a significantly decreased corrosion rate $\left(2.11 \rightarrow 0.13 \mathrm{~mm}^{\cdot} \mathrm{year}^{-1}\right)$. However, the corrosion rates of GZ101 and GZ101-1Zr calculated from potentiodynamic polarization curves equaled 0.67 and $0.15 \mathrm{~mm} \cdot$ year $^{-1}$, respectively, indicating the significant effect of analysis conditions such as test time and exposure area. In addition, a much higher corrosion current density was observed for extruded GZ101-1Zr (Fig. 4(b)). The electrochemical corrosion parameters are summarized in Table 2.

As reported previously, ${ }^{18,20)}$ the addition of $\mathrm{Zr}$ to $\mathrm{Mg}$ $\mathrm{Gd}-\mathrm{Zn}$ alloys results in the formation of a $\mathrm{ZnZr}$ phase, and hinders the formation of LPSO structure due to causing $\mathrm{Zn}$ consumption. Therefore, the formation of $14 \mathrm{H}$ and lamellar LPSO phases in GZ101-1Zr was suppressed, as shown in Figs. 1 (c) and (d). Furthermore, the above addition did not induce significant shape changes for the X-phase formed at grain boundaries in GZ101-1Zr, whereas $14 \mathrm{H}$ and lamellar LPSO phases were broken up into small particles in the extruded GZ101 sample. Therefore, a stronger PSN effect was observed for the X-phase than for $14 \mathrm{H}$ and lamellar LPSO phases, resulting in microstructure recrystallization (Figs. 2 (a) and (b)).

The obtained results indicated that the addition of $\mathrm{Zr}$ resulted in significantly microstructure change and increased

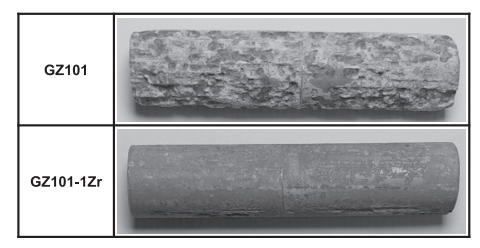

(a)

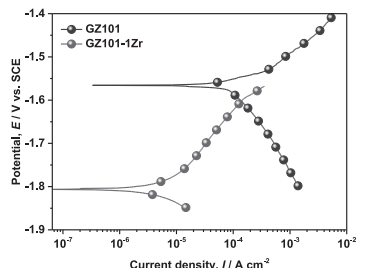

(b)
Fig. 4 (a) Corrosion morphology after immersion test for 7 days and (b) potentiodynamic polarization curves of the extruded alloys in 3.5 mass\% $\mathrm{NaCl}$ solution at $298 \mathrm{~K}$.

corrosion resistance. Moreover, EBSD analysis indicated that $\mathrm{Zr}$ addition not only improved the distribution of small deformed grains but also decreased the size of recrystallized grains formed after extrusion in GZ101-1Zr (Figs. 3 (a)-(f)). The smaller recrystallized grains had a random texture, whereas the deformed grains had a strong in $\{10 \overline{1} 0\}$ prismatic texture in the extrusion direction, as shown in Figs. 3 (g) and (h). Overall, the corrosion resistance of extruded alloys was improved by $\mathrm{Zr}$ addition, in line with the wellknown fact that phase and texture microstructural features are closely related to the corrosion behavior of $\mathrm{Mg}$ alloys. $7,8,21$ )

Extruded GZ101-1Zr exhibited the more stable corrosion morphology than GZ101 and featured a significantly smaller corrosion current density (Figs. 4 (a) and (b)). These results were attributed to the decreased fraction of $14 \mathrm{H}$ and lamellar phases (which had a continuous net-like shape in $\mathrm{Mg}$ matrix grains and deteriorated corrosion resistance due to promoting the generation of micro-galvanic sites) in the former alloy. $^{21)}$

From the viewpoint of galvanic couple formation, the above behavior was expected to suppress the partial cathodic reaction and reduce corrosion current density during the cor- 
rosion process. However, X-phase formation at alloy grain boundaries enhanced corrosion resistance due to acting as a corrosion barrier. ${ }^{22)}$ Furthermore, in extruded GZ101-1Zr, almost all grains exhibited a $\{10 \overline{1} 0\}$ prismatic texture in the extrusion direction and featured a homogeneous size distribution. In general, it is known that the corrosion resistance of the basal plane superior wrought magnesium alloys due to the packing density of the atoms in the crystallographic anisotropy in the HCP structure. ${ }^{7,8)}$ Also, it can be seen that the reduced corrosion rate influenced by the grains with (0002) preferential orientation with newly deformed $\{10 \overline{1} 0\}$ prismatic texture to the ED during extrusion, due to the more difficult to corrode away, since the corrosion current density effectively decreased of the $\mathrm{Mg}$ matrix grain when exposed an aqueous solution. ${ }^{7)}$

\section{Conclusions}

Herein, we investigated the corrosion resistance of extruded $\mathrm{Zr}$-doped (GZ101-1Zr) and non-doped (GZ101) $\mathrm{Mg}$ alloys in 3.5 mass \% NaCl solution, revealing that $\mathrm{Zr}$ doping decreased the fraction of $14 \mathrm{H}$ and lamellar LPSO phases. Additionally, extruded GZ101-1Zr exhibited a much smaller corrosion rate than extruded GZ101 (0.13 vs. $2.11 \mathrm{~mm} \cdot$ year $^{-1}$ ) due to containing smaller amounts of $14 \mathrm{H}$ and lamellar LPSO phases (detrimental to corrosion resistance) and exhibiting a $\{10 \overline{1} 0\}$ prismatic texture in the extrusion direction. The above changes led to the basal plane being inclined to the sample normal direction (surface) and significantly decreased the corrosion rate of extruded GZ101-1Zr in aqueous $\mathrm{NaCl}$ solutions.

\section{Acknowledgements}

This study was financially supported by the Important Defense Materials Technology Development project funded by the Korea Ministry of Industrial, Trade and Energy (Project No. NRF 10043821) Korea Government.

\section{REFERENCES}

1) J. Hirsch and T. Al-Samman: Acta Mater. 61 (2013) 818-843.

2) G.Y. Yuan, Z.L. Liu, Q.D. Wang and W.J. Ding: Mater. Lett. 56 (2002) 53-58.

3) M.O. Pekguleryuz and A.A. Kaya: Adv. Eng. Mater. 5 (2003) 866-878.

4) A. Srinivasan, Y. Huang, C.L. Mendis, H. Dieringa, C. Blawert, K.U. Kainer and N. Hort: Mater. Sci. Forum 765 (2013) 28-32.

5) M. Yamasaki, M. Sasaki, M. Nishijima, K. Hiraga and Y. Kawamura: Acta Mater. 55 (2007) 6798-6805.

6) T. Honma, T. Ohkubo, S. Kamado and K. Hono: Acta Mater. 55 (2007) 4137-4150.

7) G. Song (Ed.), Corrosion of Magnesium Alloys, WP Publishing (2011) 46-51.

8) M. Liu, D. Qiu, M.-C. Jhao, G. Song and A. Atrens: Scr. Mater. 58 (2008) 421-424.

9) A. Srinivasan, Y. Huang, C.L. Mendis, C. Blawert, K.U. Kainer and N. Hort: Mater. Sci. Eng. A 595 (2014) 224-234.

10) K.R. Athul, A. Srinivasan, U.T. Subramonia Pillai and B. Chandrasekhara Pai: Mater. Sci. Forum 830 (2015) 631-634.

11) C. Wang, M. Sun, F. Zheng, L. Peng and W. Ding: J. Mag. and Alloys 2 (2014) 239-244.

12) M. Sun, G. Wu, W. Wang and W. Ding: Mater. Sci. Eng. A 523 (2009) 145-151.

13) M. Yang, H. Li, R. Cheng, F. Pan and H. Hu: Mater. Sci. Eng. A 545 (2012) 201-208.

14) M. Yuasa, X. Huang, K. Suzuki, M. Mabuchi and Y. Chino: Mater. Trans. 55 (2014) 1202-1207.

15) Annual Book of ASTM Standards, ASTM G5.

16) M. Yamasaki, T. Anan, S. Yoshimoto and Y. Kawamura: Scr. Mater. 53 (2005) 799-803.

17) M. Yamasaki, M. Sasaki, M. Nishijima, K. Hiraga and Y. Kawamura: Acta Mater. 55 (2007) 6798-6805.

18) J.H. Li, J. Barrirero, G. Sha, H. Aboulfadl, F. Mücklich and P. Schumacher: Acta Mater. 108 (2016) 207-218.

19) J.G. Jung, S.H. Park, H. Yu, Y.M. Kim, Y.-K. Lee and B.S. You: Scr. Mater. 93 (2014) 8-11.

20) W. Rong, Y. Zhang, Y. Wu, M. Sun, J. Chen, Y. Wang, J. Han, L. Peng and H. Ding: J. Alloy. Compd. 692 (2017) 805-816.

21) A. Srinivasan, C. Blawert, Y. Huang, C.L. Mendis, K.U. Kainer and N. Hort: J. Mag. And Alloys 2 (2014) 245-256.

22) J. Zhang, J. Xu, W. Cheng, C. Chen and J. Kang: J. Mater. Sci. Technol. 28 (2012) 1157-1162. 